\title{
Market Basket Analysis dengan Algoritma Apriori pada Ecommerce Toko Busana Muslim Trendy
}

\section{(Market Basket Analysis with Apriori Algorithms in Ecommerce Trendy Muslim Clothing Stores)}

\author{
Aji Setiawan', Rizka Mulyanti² \\ ${ }^{1,2}$ Jurusan Teknik Informatika, Fakultas Teknik, Universitas Darma Persada, Jakarta \\ Jln. Terusan Casablanca, Pondok Kelapa, Jakarta, Indonesia \\ 1 aji_setiawaneft.unsada.ac.id \\ 2 risqa24@gmail.com
}

\begin{abstract}
Abstrak- Teknologi yang terus berkembang diera modern khususnya di bidang e-commerce memerlukan suatu pendekatan yang bersifat ekslusif, dimana pelanggan dapat dengan mudah menemukan barang yang dinginkan dengan rekomendasi sistem yang tepat. Namun beberapa permasalahan sering dijumpai bahwa rekomendasi yang ditawarkan oleh sistem tidak cukup membantu, karena rekomendasi yang ditawarkan tidak berdasarkan transkasi konsumen tersebut, dengan kata lain belum memanfaatkan data mining. Penelitian ini mencoba menerapkan data mining dengan sebuah algoritma yang dapat memprediksi barang yang akan dibeli konsumen selanjutnya. Dalam penelitian ini pengembangan sistem dibangun dengan pendekatan Market Basket Analysis (MBA) untuk menentukan produk mana yang akan dibeli oleh konsumen berdasarkan analisa terhadap daftar transaksi pelanggan dan metode perancangan sistem yang digunakan pada pembuatan aplikasi ini menggunakan pendekatan model waterfall, diawali dengan tahap analisa dengan wawancara dan pengambilan data penjualan, dilanjutkan design aplikasi, tahap coding, testing dan maintenance. Hasil dari data pengujian fungsional berdasarkan pengujian test case menunjukkan bahwa sistem dapat bekerja sesuai dengan tujuan penelitian dan membantu pelanggan menentukan pilihan berdasarkan produk yang dibeli sebelumnya.
\end{abstract}

Kata-kata Kunci - Market Basket Analysis (MBA), algorithms apriori, waterfall, ecommerce

Abstract - Technology that continues to develop in the modern era, especially in the field of e-commerce requires a selective approach, where customers can easily find the desired items with the right system recommendations. However, some problems often found that the recommendations offered by the system are not enough to help because the recommendations offered not to base on consumer transactions; in other words, not yet utilising data mining. This research tries to apply data mining with an algorithm that can predict the items consumers will buy next. In this study the development of the system was built with the Market Basket Analysis (MBA) approach to determine which products will be purchased by consumers based on an analysis of the list of customer transactions and system design methods used in making this application using the waterfall model approach, beginning with the analysis phase with interviews and sales data collection, followed by application design, coding, testing and maintenance stages. The results of functional testing data based on test case testing show that the system can work by research objectives and help customers make choices based on previously purchased products.

Keywords - Market Basket Analysis (MBA), apriori algorithm, waterfall, e-commerce

\section{PENDAHULUAN}

Kemajuan teknologi informasi dengan sarana komunikasi internet saat ini telah berkembang sangat pesat. Berbagai media elektronik dibuat untuk mendukung kecepatan informasi mulai dari notebook, pc, hingga smartphone digunakan untuk melakukan komunikasi dan bisnis. Tingginya tingkat persaingan dalam dunia bisnis mengharuskan perusahaan agar dapat memberikan respon yang cepat kepada pelanggan agar proses transaksi tidak harus antri dalam menunggu respon penjual. Permasalahan lain yang juga muncul adalah kesulitan dalam menganalisis data transaksi penjualan pun sering dihadapi suatu perusahaan karena banyaknya jumlah data dan keterbatasan alat pengolah data. Hal tersebut berakibat tidak tepatnya hasil rekomendasi terhadap item bagi pelanggan dan yang terjadi adalah pembelian konsumen menurun dikarenakan tidak cocok model yang ditawarkan. E- 
Commerce adalah salah satu teknologi yang bisa dijadikan pemecah masalah tersebut, dimana ecommerce diharapkan dapat membantu perusahaan dalam mengembangkan bisnisnya. Toko Busana Muslim Trendy merupakan suatu Usaha Kecil dan Menengah (UKM) di bintara bekasi jawa barat, yang mengembangkan bisnisnya pada bidang fashion khususnya busana muslim. Produk yang dijual berupa pakaian wanita, mulai dari gamis syar'i, dress, abaya, mukena dan lain sebagainya. Selama ini toko online Busana Muslim Trendy mengembangkan bisnisnya dengan media terbatas dan dalam lingkup pemasaran yang kecil serta kesulitan mengolah data transaksi penjualan.

Data mining saat ini sudah banyak digunakan dalam berbagai penelitian diantaranya dalam dunia pendidikan [1], medis [2], dunia industri [3], hingga jual beli [4]. Metode Market Basket Analysis (MBA) juga dikenal sebagai association rules atau analisis afinitas, adalah teknik penambangan data yang berasal dari bidang pemasaran dan baru-baru ini telah digunakan secara efektif di bidang lain, seperti bioinformatika, ilmu nuklir, pharmacoepidemiology, imunologi, dan geofisika [5]. Beberapa penelitian pendahuluan dengan metode MBA dengan algoritma apriori dilakukan pada data transaksi penjualan kartu perdana [6], penggunaan metode MBA pada bidang retail [7] dan penjualan buku [8]. Sistem data mining yang telah dibangun dengan metode MBA digunakan untuk memberikan rekomendasi terhadap pembelian produk bagi pelanggan berdasarkan keterikatan produk yang telah dibeli sebelumnya.

\section{METODE}

Metode penelitian dimulai dari tahap pengumpulan data dengan wawancara dan pengambilan data penjualan berupa berkas penjualan harian dan rekap bulanan. Data didapatkan dari hasil visitasi ke lokasi penelitian, selanjutnya data dianalisa menggunakan MBA (Market Basket Analysis) dengan algoritma apriori untuk dilihat tingkat korelasi antara penggunaan metode dengan data riil penjualan dilapangan. Sistem pengembangan menggunakan algoritma apriori seperti pada gambar 1 [9].

Dalam penelitian ini penerapan algoritma apriori dilakukan dengan mengumpulkan transaksi penjualan selama 6 bulan terakhir di toko busana muslim trendy. Setiap transaksi yang sering muncul akan dibandingkan dengan nilai confidence, sebuah item akan di eliminasi jika ada item yang lebih besar nilai confidence nya. Secara detail langkah-langkah dalam algoritma apriori sebagai berikut [10] :
A. Mencari nilai confidence dengan menjalankan 2 langkah, diantaranya:

1) Mendapatkan pola frekuensi tinggi sebuah item, atau

2) Mendapatkan pola frekuensi tinggi dua buah item.

B. Langkah berikutnya mendapatkan nilai confidence, selanjutnya pembentukan aturan asosiatif dengan algoritma apriori dengan langkah sebagai berikut [11]:

1) Menemukan association rules

2) Membuat tabel tabular

3) Membuat 2 kombinasi 2 item dataset

4) Menyeleksi frekuensi yang lebih besar atau sama dengan batas minimal yang telah ditentukan

5) Membuat 2 kombinasi 3 item dataset

Selanjutnya dalam proses pengembangan sistem menggunakan model Waterfall, karena dalam perancangan dan pembuatan sistem dilakukan secara bertahap sehingga dapat mengurangi tingkat kesalahan [12].

Perancangan sebuah sistem memerlukan metode atau langkah-langkah dalam pembangunan atau pengembangan sistem. Metode waterfall (Gambar 2) salah satu yang dapat digunakan, menekankan bahwa langkah logis dari langkah-langkah harus diambil sepanjang siklus hidup pengembangan perangkat lunak (SDLC) [12] dengan melalui beberapa tahapan penelitian.

\section{A. System Engineering}

Secara aktual diwujudkan dengan dokumen persyaratan kebutuhan sistem.

B. Analysis (Analisis Kebutuhan)

Dalam tahap ini kami melakukan analisa kebutuhan untuk menghasilkan model bisnis yang sesuai.

\section{Desain Sistem (System Design)}

Dalam tahap ini kami membuat tampilan-tampilan layout sistem yang akan dibangun dalam aplikasi.

D. Penulisan Kode Program/Implementasi (Coding \& Testing)

Dalam tahap ini kami melakukan pembuatan aplikasi dengan menggunakan kode-kode program yang sesuai dengan tujuan awal yaitu dengan pemrograman berbasis web.

\section{E. Penerapan/Pengujian Program (Integration \& Testing)}


Dalam tahap ini kami melakukan sosialisasi aplikasi dan juga pengujian, agar mengetahui ada atau tidaknya kesalahan setelah dikerjakan.
F. Pemeliharaan (Operation \& Maintenance)

Dalam tahap ini dilakukan pengembangan dan pemeliharaan terhadap sistem yang dibangun apakah nantinya ada kesalahan atau tidak.

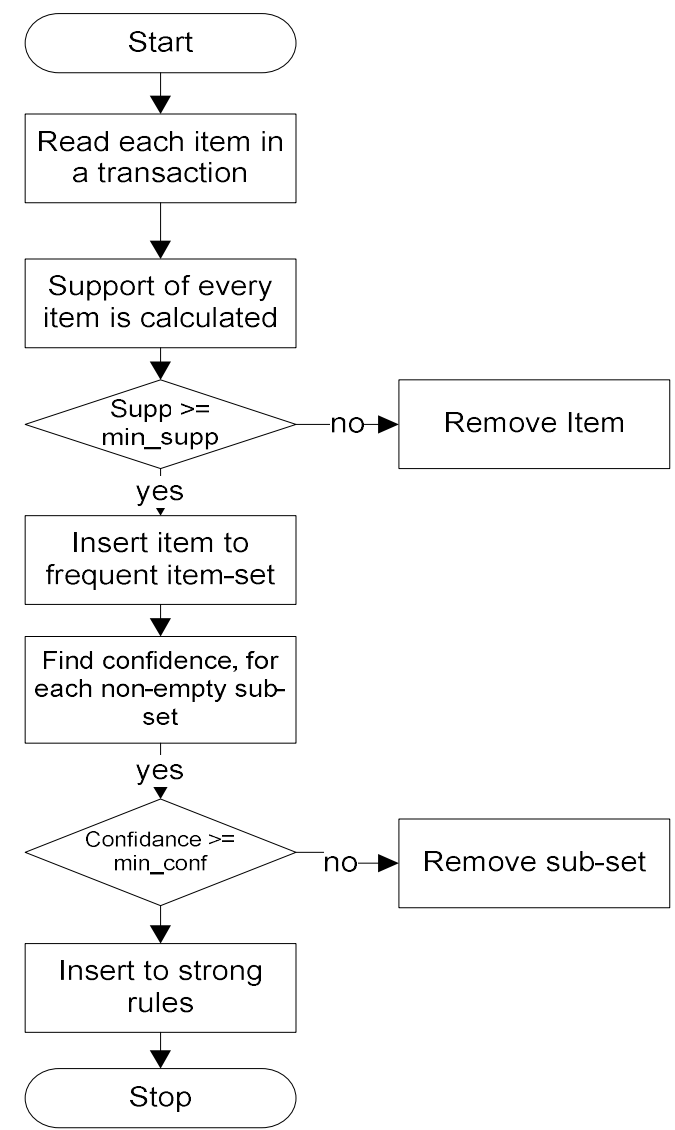

Gambar 1. Algoritma Apriori

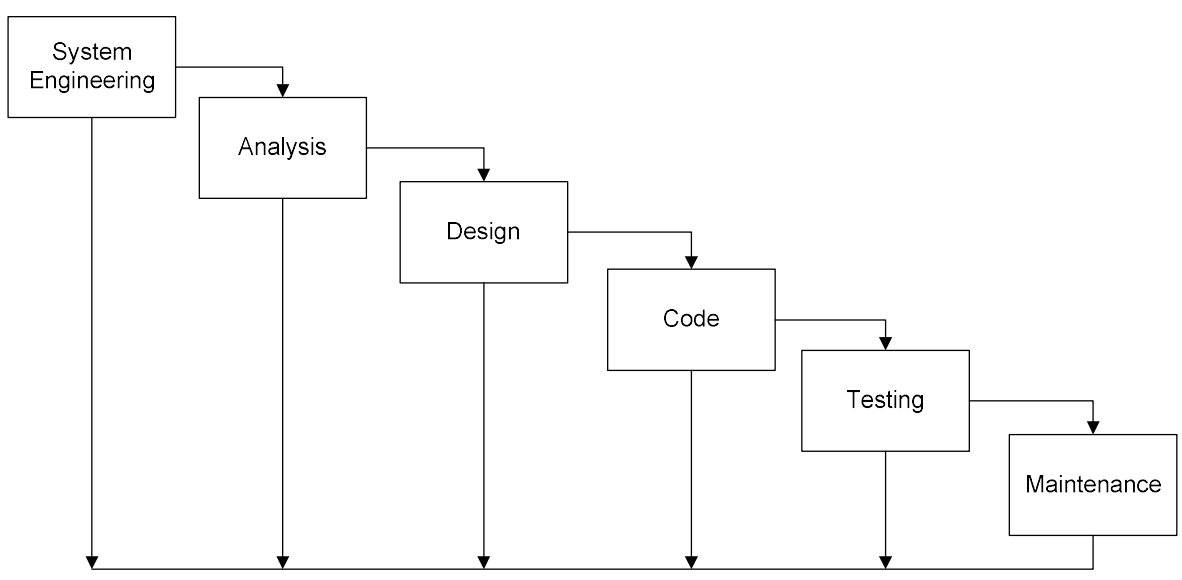

Gambar 2. Waterfall Model 


\section{HASIL DAN PEMBAHASAN}

\section{A. Proses Market Basket Analysis}

Market Basket Analysis merupakan salah satu penerapan algoritma apriori [13], market basket analysis (MBA) menekankan pada analisis pembelanjaan pelanggan untuk menganalisis kebiasaan barang yang dibeli dan menambang pola-pola tersebut dari sejumlah catatan transaksional yang dapat membantu penjual dan aplikasi dalam mengembangkan strategi pemasaran mereka untuk meningkatkan penjualan dan memaksimalkan profit. Algoritma apriori merupakan salah satu metode yang bertujuan mencari pola yang sering muncul di antara banyak transaksi, dimana setiap transaksi terdiri dari beberapa item sehingga metode ini akan mendukung system rekomendasi melalui penemuan pola antar item dalam transaksi-transaksi yang terjadi.

Algoritma apriori merupakan cabang dari data mining yang bertujuan untuk mengidentifikasi asosiasi antara berbagai item yang disimpan dalam database yang cukup besar [13]. Bentuk umum dari algoritma apriori seperti pada persamaan 1 .

$$
A 1 \ldots A n \rightarrow \mathrm{B}
$$

Pelanggan yang membeli produk A juga mempunyai peluang yang cukup besar untuk membeli produk B, dimana tidak ada batasan pada jumlah dari item-item dari sebuah rule. Bentuk lain yang lebih kompleks dari algoritma apriori seperti pada persamaan 2 .

$$
A, C \rightarrow \mathrm{B}, \mathrm{D}
$$

Pelanggan yang membeli produk $\mathrm{A}$ dan $\mathrm{C}$ juga mempunyai kecenderungan untuk membeli produk B dan D. Salah satu masalah dalam pencarian algoritma apriori adalah sangat banyaknya kemungkinan ditemukannya rules yang belum tentu merupakan rules yang baik dan dapat dipercaya. Penting tidaknya suatu aturan asosiatif dapat diketahui dengan dua parameter, yaitu support dan confidence. Support (nilai penunjang) adalah persentase kombinasi item tersebut dalam database, sedangkan Confidence (nilai kepastian) adalah kuatnya hubungan antar item dalam aturan asosiasi.

Analisis asosiasi didefinisikan sebagai suatu proses untuk menemukan semua aturan asosiasi yang memenuhi syarat minimum untuk support (minimum support) dan syarat minimum untuk confidence (minimum confidence). Jika supportnya $\geq$ minimum support dan confidencenya $\geq$ minimum confidence, maka rule tersebut bisa dikatakan sebagai interesting rule. Tahap ini mencari kombinasi item yang memenuhi syarat minimum dari nilai support dalam database. Nilai support sebuah item diperoleh dengan perhitungan seperti berikut [14] :

1) Mendapatkan frekuensi tinggi pola. Tahap untuk mencari kombinasi item yang memenuhi syarat minimum dari nilai support, dimana nilai support sebuah item diperoleh dengan rumus persamaan 3 .

$$
\text { Support }(A)=\frac{\text { Jumlah Transaksi mengandung } A}{\text { Total transaksi }}
$$

Sementara, nilai support dengan 2 item diperoleh persamaan 4 .

Support $(A, B)=\frac{\text { Jumlah Transaksi mengandung } A \text { dan } B}{\text { Total transaksi }}$

2) Pembentukan aturan asosiatif. Nilai confidence yang telah didapat akan digunakan untuk melakukan perhitungan dengan algoritma apriori, dimana algoritma ini digunakan untuk menghasilkan aturan asosiasi dengan pola if-then. Algoritma ini dapat membantu mengurangi jumlah pengulangan pencarian yang harus dilakukan. Langkah dalam menggunakan algoritma apriori melibatkan dua tahapan utama sebagai berikut [11]:

a) Tahapan pertama dalam perhitungan algoritma apriori menuliskan data transaksi yang terjadi dalam periode tertentu. Data transaksi pada objek penelitian yang didapat dari hasil observasi seperti dalam tabel 1.

b) Tahapan berikutnya adalah membuat tabel tabular untuk melakukan perhitungan jumlah transaksi penjualan. Tabular ini dapat dilihat pada tabel 2.

c) Langkah berikutnya adalah membuat kombinasi 2 itemsets pada setiap transaksi dan frekuensi masing-masing kombinasi dihitung sesuai dengan data tabular pada tabel 3 .

d) Nilai frekuensi pada masing-masing item sets selanjutnya diseleksi untuk melihat frekuensi yang lebih besar atau sama dengan batas minimal yang telah ditentukan. Misalnya ditentukan batas minimal support $\geq 2$ seperti terdapat pada tabel 4.

e) Tabel kombinasi 2 itemsets pada tabel 4 adalah kombinasi yang memenuhi batas minimal support. Berdasarkan tabel diatas tahap selanjutnya adalah membuat kombinasi 3 item sets seperti terlihat pada tabel 5 .

f) Pada kombinasi 3 itemsets sering tidak ada yang memenuhi minimal support $\geq 2$ maka hanya menggunakan pola kombinasi 2 itemsets. Jumlah confidence dari pola kombinasi 2 itemsets yang memenuhi minimal support seperti pada tabel 6 . 
g) Menetapkan nilai confidence, misalkan ditetapkan nilai confidence minimal adalah $60 \%$ maka terlebih dahulu kita menyeleksi jumlah minimal confidence. Dari tabel VI diatas maka dapat dihitung aturan asosiasi finalnya, yaitu Support $\times$ Confidence sehingga didapatkan data table 7.

TABEL I

DAFTAR PRODUK

\begin{tabular}{|c|c|c|c|c|c|}
\hline Transaksi & \multicolumn{5}{|c|}{ Produk yang dibeli } \\
\hline 1 & \multicolumn{5}{|c|}{ Nafisha Syar'i, Furzana Syar'i, Gloria Syar'i } \\
\hline 2 & \multicolumn{5}{|c|}{ Gloria Syar'i, Furzana Syar'i, Anindya syar'i } \\
\hline 3 & \multicolumn{5}{|c|}{ Gloria Syar'i, Nafisha Syar'i, Anindya syar'i } \\
\hline 4 & \multicolumn{5}{|c|}{ Gloria Syar'i, Anindya syar'i, Maxi Atalia } \\
\hline \multicolumn{6}{|c|}{$\begin{array}{c}\text { TABEL II } \\
\text { TABULASI TRANSAKSI }\end{array}$} \\
\hline $\begin{array}{c}\text { ID } \\
\text { Transaksi } \\
\end{array}$ & $\begin{array}{c}\text { Nafisha } \\
\text { Syar'i } \\
\end{array}$ & $\begin{array}{c}\text { Furzana } \\
\text { Syar'i } \\
\end{array}$ & $\begin{array}{l}\text { Gloria } \\
\text { Syar'i }\end{array}$ & $\begin{array}{c}\text { Anindya } \\
\text { Syar'i }\end{array}$ & $\begin{array}{r}\text { Maxi } \\
\text { Atalia } \\
\end{array}$ \\
\hline 1 & 1 & 1 & 1 & 0 & 0 \\
\hline 2 & 0 & 1 & 1 & 1 & 0 \\
\hline 3 & 1 & 0 & 1 & 1 & 0 \\
\hline 4 & 0 & 0 & 1 & 1 & 1 \\
\hline Jumlah & 2 & 2 & 4 & 3 & 1 \\
\hline
\end{tabular}

TABEL III KOMBINASI 2 ITEMSET

\begin{tabular}{lc}
\hline \multicolumn{1}{c}{ Pola Kombinasi 2 Itemset } & Qty \\
\hline Gloria Syar'i - Anindya syar'i & 3 \\
Nafisha Syar'i - Gloria Syar'i & 2 \\
Furzana Syar'i - Gloria Syar'i & 2 \\
Nafisha Syar'i - Furzana Syar'i & 1 \\
Nafisha Syar'i - Anindya syar'i & 1 \\
Furzana Syar'i - Anindya syar'i & 1 \\
Gloria Syar'i - Maxi Atalia & 1 \\
Anindya syar'i - Maxi Atalia & 1 \\
\hline \multicolumn{2}{c}{ TABEL IV } \\
\multicolumn{2}{c}{ KOMBINASI 2 ITEMSET } \\
\hline Pola Kombinasi 2 Itemset & Qty \\
\hline Gloria Syar'i - Anindya syar'i & 3 \\
Nafisha Syar'i - Gloria Syar'i & 2 \\
Furzana Syar'i - Gloria Syar'i & 2 \\
\hline
\end{tabular}

TABEL V

KOMBINASI 3 ITEMSET

\begin{tabular}{lc}
\hline \multicolumn{1}{c}{ Pola Kombinasi 3 Itemset } & Qty \\
\hline Jika pelanggan membeli Nafisha Syar'i dan Furzana Syar'i maka barang berikutnya yang & 1 \\
dibeli adalah GLORIA SYARI & 1 \\
Jika pelanggan membeli Nafisha Syar'i dan Anindya syar'i & 1 \\
maka barang berikutnya yang dibeli adalah GLORIA SYARI & 1 \\
Jika pelanggan membeli Furzana Syar'i dan Anindya syar'i & 1 \\
maka barang berikutnya yang dibeli adalah GLORIA SYARI & 1 \\
Jika pelanggan membeli Maxi Atalia maka barang berikutnya yang dibeli adalah GLORIA & 1 \\
SYARI dan Anindya syar'i & 1 \\
Jika pelanggan membeli GLORIA SYARI dan Maxi Atalia & 1 \\
Jika pelanggan membeli Anindya syar'i dan Maxi Atalia & \\
maka barang berikutnya yang dibeli adalah GLORIA SYARI & \\
\hline
\end{tabular}

TABEL VI

SELEKSI MINIMUM CONFIDENCE

\begin{tabular}{lcc}
\hline \multicolumn{1}{c}{ Pola Kombinasi 2 Itemset } & Confidence \\
\hline Jika pelanggan membeli Furzana Syar'i maka barang berikutnya yang dibeli & $2 / 2$ & $100 \%$ \\
adalah Gloria Syari & & \\
Jika pelanggan membeli Nafisha Syar'i maka barang berikutnya yang dibeli & $2 / 2$ & $100 \%$ \\
adalah Gloria Syari & $3 / 3$ & $100 \%$ \\
Jika pelanggan membeli Anindya Syar'i maka barang berikutnya yang dibeli \\
$\begin{array}{l}\text { adalah Gloria Syari } \\
\text { Jika pelanggan membeli Gloria Syarimaka barang berikutnya yang dibeli adalah }\end{array}$ \\
$\begin{array}{l}\text { Anindya Syar'i } \\
\text { Jika pelanggan membeli Maxi Atalia maka barang berikutnya yang dibeli adalah } \\
\text { Anindya Syar'i }\end{array}$ & $1 / 4$ & $75 \%$ \\
$\begin{array}{l}\text { Jika Pelanggan membeli Maxi Atalia maka barang berikutnya yang dibeli } \\
\text { adalah Gloria Syari }\end{array}$ & $1 / 1$ & $100 \%$ \\
\hline
\end{tabular}


TABEL VII

FINAL ASSOCIATION RULES

\begin{tabular}{|c|c|c|c|}
\hline Pola Kombinasi 2 Itemset & Support & Confidence & $\begin{array}{c}\text { Support } \mathbf{x} \\
\text { Confidence }\end{array}$ \\
\hline $\begin{array}{l}\text { Jika pelanggan membeli Nafisha Syar'i maka barang berikutnya } \\
\text { yang dibeli adalah Gloria Syari. }\end{array}$ & $50 \%$ & $100 \%$ & $50 \%$ \\
\hline $\begin{array}{l}\text { Jika pelanggan membeli Furzana Syar'i maka barang berikutnya } \\
\text { yang dibeli adalah Gloria Syari. }\end{array}$ & $50 \%$ & $100 \%$ & $50 \%$ \\
\hline $\begin{array}{l}\text { Jika pelanggan membeli Anindya syar'i maka barang berikutnya } \\
\text { yang dibeli adalah Gloria Syari. }\end{array}$ & $75 \%$ & $100 \%$ & $75 \%$ \\
\hline $\begin{array}{l}\text { Jika pelanggan membeli Gloria Syari maka barang berikutnya yang } \\
\text { dibeli adalah Anindya syar'i. }\end{array}$ & $75 \%$ & $75 \%$ & $56,25 \%$ \\
\hline
\end{tabular}

Tabel final association rule menjelaskan tentang support dan confidence dari masing-masing kombinasi 2 itemsets. Hasil perhitungan support didapatkan dari jumlah kombinasi item A dan B dibagi dengan total transaksi yang ada. Sedangkan confidence didapatkan dari jumlah transaksi dengan kombinasi item A dan B dibagi dengan total transaksi A. Hasil perkalian support dan confidence itulah yang menjadi hasil akhir dari algoritma apriori, berdasarkan tabel 7 didapatkan nilai tertinggi $75 \%$ dimana jika pelanggan membeli Anindya syar'i maka barang berikutnya yang dibeli adalah Gloria Syari.

\section{B. Pengembangan Sistem}

1) Definisi Persyaratan (Requirement Analysis and Definition). Dalam melakukan definisi persyaratan ini menggunakan suatu analisis yaitu analisis sistem, analisis proses, dan analisis output.

a) Analisis sistem. Tidak tersedianya system informasi untuk melakukan rekap penjualan sehingga menyulitkan pemilik untuk menentukan pesanan model ke suplier. Selama ini setiap transaksi direkap dalam bentuk kertas dan sering terjadi kehilangan mupun rusak.

b) Analisis Proses. Pembeli yang ingin melakukan pembelian barang diharuskan mendaftarkan akun pada sistem ecommerce. Setelah itu, pembeli dapat memilih produk yang akan dibeli jika sudah barang tersebut akan masuk dalam list pembelian, pembeli selanjutnya dapat mentransfer dan mengupload bukti transfer selanjutnya dapat melihat status pengiriman barang.

c) Analisis output. Setiap barang yang berhasil terjual akan tercatat dalam laporan pembelian yang nantinya dapat dilihat rekapitulasi penjualan harian dan bulanan. Pelanggan yang telah tercatat melakukan pembelian akan direkomendasikan produk lain yang memiliki hubungan dengan barang yang dibeli sebelumnya berdasarkan metode market basket analisis (MBA).

2) Perancangan Sistem dan Perangkat Lunak (System and Software Design). ERD digunakan untuk mewakili dekomposisi domain subjek suatu sistem menjadi entitas. ERD terdiri dari node, yang mewakili tipe entitas, dan edge, yang mewakili hubungan [15]. Tabel ERD sistem yang dibangun dapat dilihat pada Gambar 3.

Selanjutnya melakukan perancangan UML pada proses development system, berikut adalah use case diagram yang mendeskripsikan gambaran terkait aplikasi yang dibangun sebagaimana terlihat pada gambar 4.

Pada gambar 4 admin dapat menggunakan fitur-fitur yang tersedia pada sistem seperti login, menginput mengedit dan menghapus data barang, melihat data barang dan data barang masuk keluar, melihat hasil kelola metode market basket analisis (MBA).

\section{3) Implementasi}

Pada hak akses admin, admin dapat melihat hasil dari pola analisa dengan memilih menu kelola MBA lalu mengisi form kelola MBA seperti pada gambar 5 diatas dengan memilih jangka waktu yang akan diolah dan memasukkan minimum support/ itemset sering muncul, nilai confidence dan maximum kombinasi. Halaman ini dapat digunakan oleh admin untuk memeriksa kesesuaian yang ada pada cart di halaman pelanggan.

Gambar 6 adalah halaman untuk melihat hasil analisa pola pembelian, pada halaman ini admin harus memilih menu kelola MBA dan mengisi form kelola MBA dengan memilih jangka waktu yang akan diolah dan memasukkan minimum support/itemset yang sering muncul, selanjutnya nilai confidence dan maximum akan menampilkan itemset yang sering muncul. Nilai support dari hasil analisa pola transaksi pelanggan 
dihitung dengan menggunakan metode market basket anaysis.

Untuk melihat hasil analisa pola pembelian, admin harus memilih menu kelola MBA dan mengisi form kelola MBA dengan memilih jangka waktu yang akan diolah dan memasukkan nilai confidence. Selanjutnya akan terlihat itemset sering dan nilai support dari hasil analisa pola transaksi pelanggan dihitung dengan menggunakan market basket analysis seperti halaman yang telihat gambar 7 .

Gambar 8 merupakan halaman rekomendasi tampilan untuk pelanggan, pada laman ini pelanggan dapat melihat produk-produk rekomendasi dari hasil analisa pola pembelian pelanggan yang telah dihitung dengan menggunakan metode algoritma apriori.

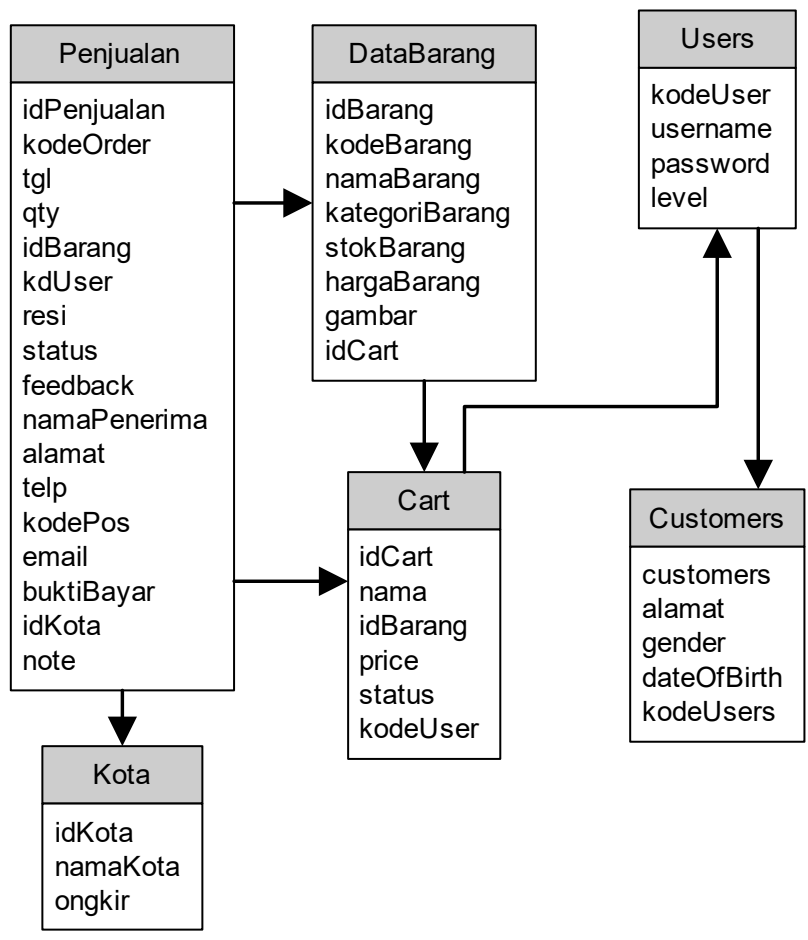

Gambar 3. Diagram ERD

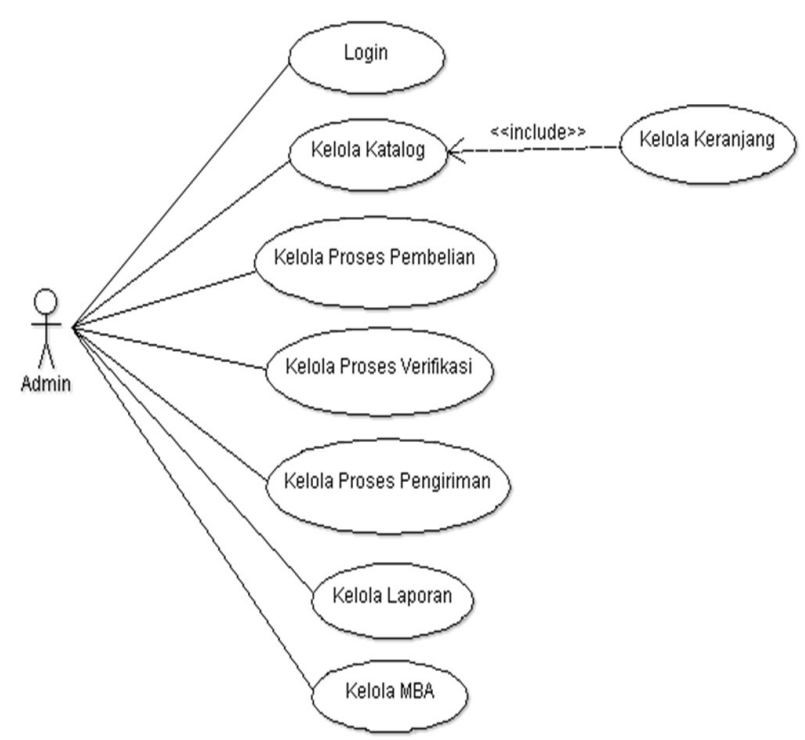

Gambar 4. Use case diagram admin

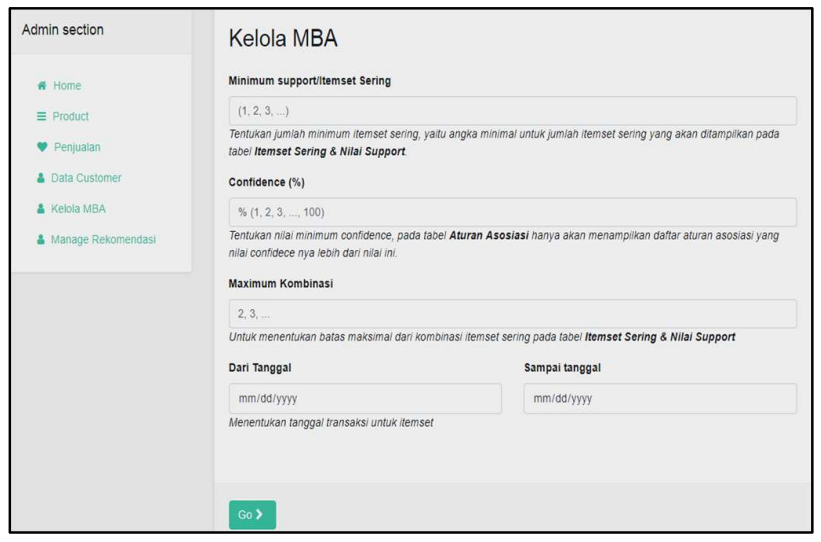

Gambar 5. Halaman kelola MBA

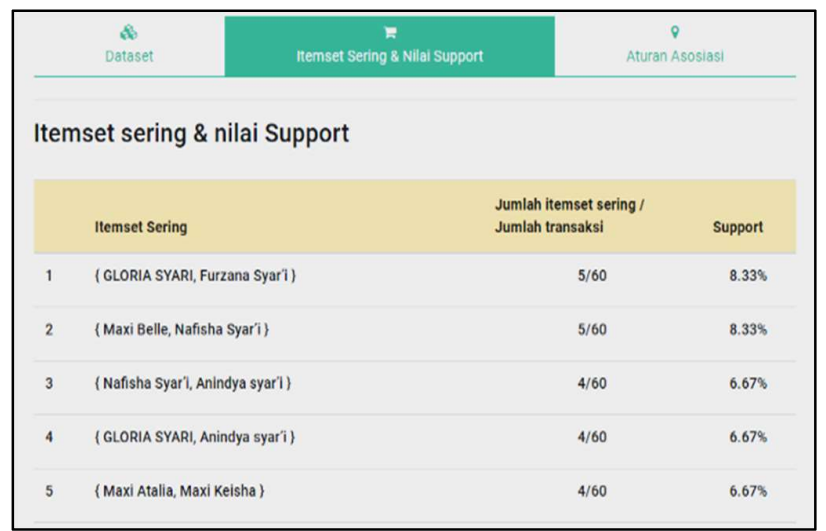

Gambar 6. Hasil analisa pola pembelian 


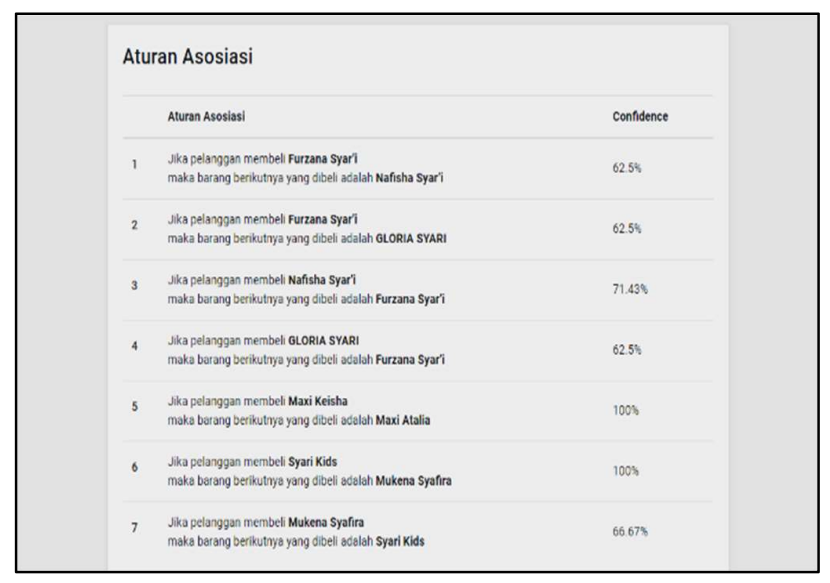

Gambar 7. Halaman aturan asosiasi

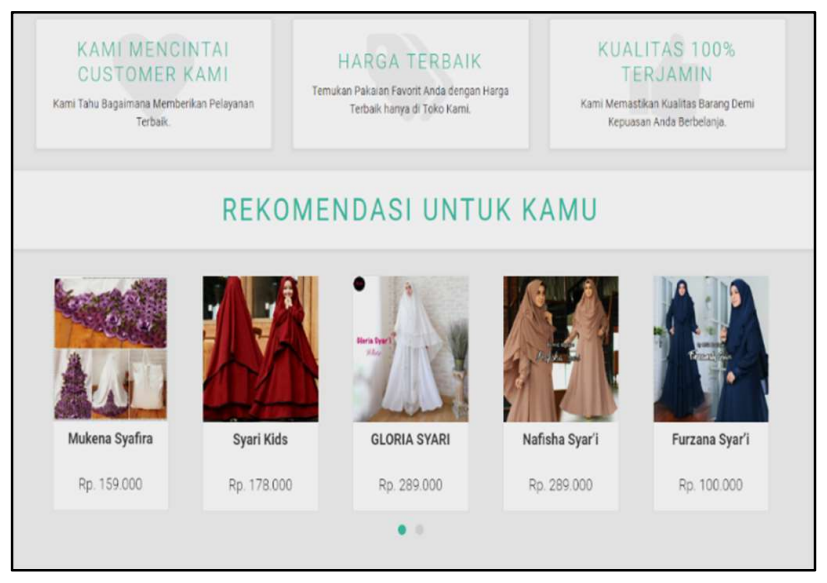

Gambar 8. Halaman Rekomendasi

\section{PENUTUP}

Berdasarkan pengujian aplikasi melalui wawancara kepada pengguna, apikasi yang dibangun dengan pendekatan market basket analisis (MBA) dengan algoritma apriori dapat membantu pelanggan dalam memilih produk yang akan dibeli dengan melihat halaman rekomendasi produk, sistem ini selain membantu merekomendasikan produk kepada pelanggan juga dapat membantu admin untuk melakukan analisa pola transaksi pembelian pelanggan. Saran yang dapat diberikan setelah penelitian ini dapat menerapkan algoritma lain untuk menemukan pola asosiasi misal dengan pendekatan teorema naïve bayes atau pendekatan machine learning.

\section{DAFTAR PUSTAKA}

[1] R. Asif, A. Merceron, S. A. Ali, and N. G. Haider, “Analyzing undergraduate students' performance using educational data mining," Comput. Educ., 2017.

[2] A. Azevedo, "Data Mining and Knowledge Discovery in Databases," in Encyclopedia of Information Science and Technology, Fourth Edition, 2017.

[3] P. Vazan, D. Janikova, P. Tanuska, M. Kebisek, and Z. Cervenanska, "Using data mining methods for manufacturing process control," IFAC-PapersOnLine, 2017.

[4] R. A. E. D. Ahmeda, M. E. Shehaba, S. Morsya, and N. Mekawiea, "Performance study of classification algorithms for consumer online shopping attitudes and behavior using data mining," in Proceedings - 2015 5th International Conference on Communication Systems and Network Technologies, CSNT 2015, 2015.

[5] H. Aguinis, L. E. Forcum, and H. Joo, "Using Market Basket Analysis in Management Research," J. Manage., 2013.

[6] U. Baetulloh, A. I. Gufroni, and R. -, "Penerapan Metode Association Rule Mining Pada Data Transaksi Penjualan Produk Kartu Perdana Kuota Internet Menggunakan Algoritma Apriori," Simetris J. Tek. Mesin, Elektro dan Ilmu Komput., 2019.

[7] R. B. Jeyavathana and K. S. D. Surath, "An efficient Frequent Pattern algorithm for Market Basket Analysis," Int. J. Recent Eng. Res. Dev., 2017.

[8] G. Gunadi and D. I. Sensuse, "Penerapan Metode Data Mining Market Basket Analysis Terhadap Data Penjualan Produk Buku Dengan Menggunakan Algoritma Apriori Dan Frequent Pattern Growth ( FpGrowth ) :," Telematika, 2012.

[9] M. Mittal, S. Pareek, and R. Agarwal, "Efficient Ordering Policy for Imperfect Quality Items Using Association Rule Mining," in Encyclopedia of Information Science and Technology, Third Edition, 2014.

[10] E. T. L. Kusrini, Algoritma Data Mining. 2009.

[11] J. Han, M. Kamber, and J. Pei, Data Mining: Concepts and Techniques. 2012.

[12] A. Powell-Morse, "Waterfall Model: What Is It and When Should You Use It?," Airbrake, 2016. .

[13] D. Gupta and H. Arora, "Market Basket Analysis using Apriori and Correlation Measures," Int. J. Innov. Res. Sci., 2017.

[14] D. Listriani, A. H. Setyaningrum, and F. Eka, "PENERAPAN METODE ASOSIASI MENGGUNAKAN ALGORITMA APRIORI PADA APLIKASI ANALISA POLA BELANJA KONSUMEN (Studi Kasus Toko Buku Gramedia Bintaro)," J. Tek. Inform., 2019.

[15] R. J. Wieringa, "Entity-Relationship Diagrams," in Design Methods for Reactive Systems, 2007. 